\title{
The role of deleterious mutations in the stability of hybridogenetic water frog complexes
}

\author{
Pasquale Bove ${ }^{1}$, Paolo Milazzo ${ }^{1}$ and Roberto Barbuti ${ }^{1,2^{*}}$
}

\begin{abstract}
Background: Some species of water frogs originated from hybridization between different species. Such hybrid populations have a particular reproduction system called hybridogenesis. In this paper we consider the two species Pelophylax ridibundus and Pelophylax lessonae, and their hybrids Pelophylax esculentus. P. lessonae and P. esculentus form stable complexes (L-E complexes) in which P. esculentus are hemiclonal. In L-E complexes all the transmitted genomes by $P$. esculentus carry deleterious mutations which are lethal in homozygosity.

Results: We analyze, by means of an individual based computational model, L-E complexes. The results of simulations based on the model show that, by eliminating deleterious mutations, L-E complexes collapse. In addition, simulations show that particular female preferences can contribute to the diffusion of deleterious mutations among all $P$. esculentus frogs. Finally, simulations show how $L-E$ complexes react to the introduction of translocated $P$. ridibundus.

Conclusions: The conclusions are the following: (i) deleterious mutations (combined with sexual preferences) strongly contribute to the stability of L-E complexes; (ii) female sexual choice can contribute to the diffusion of deleterious mutations; and (iii) the introduction of P. ridibundus can destabilize L-E complexes.
\end{abstract}

Keywords: Hybridogenesis, Water frogs, Sexual selection, Computational models, Simulations

\section{Background}

Lake frog (Pelophylax ridibundus Pallas, 1771) and pool frog (Pelophylax lessonae Camerano, 1882) can mate producing the hybrid edible frog (Pelophylax esculentus Linneus, 1758). P. esculentus can coexist with one or both of the parental species giving rise to mixed populations. Usually, the genotypes of $P$. ridibundus, $P$. lessonae and $P$. esculentus are indicated by $R R, L L$, and $L R$, respectively. In Europe there are mixed populations containing $P$. ridibundus and $P$. esculentus individuals, called R-E systems, populations with $P$. lessonae and $P$. esculentus individuals, called L-E systems, and populations with all three species. Due to the eastern origin of $P$. ridibundus, R-E complexes are frequently found in Eastern Europe, while L-E systems are widespread throughout the rest of Europe

*Correspondence: barbuti@di.unipi.it

1 Dipartimento di Informatica, Università di Pisa, Largo B. Pontecorvo, 3, 56127 Pisa, Italy

${ }^{2}$ Museo di Storia Naturale, Università di Pisa, Via Roma, 79, 56011 Calci (Pisa), taly
[1-5]. Hybrids in these populations reproduce in a particular way, called hybridogenesis [1,6-12]. Hybridogenesis consists of a gametogenetic process in which the hybrids exclude one of their parental genomes premeiotically, and transmit the other genome, clonally, to eggs and sperm. For example, in L-E complexes, P. esculentus hybrids have both the genomes of the parental species, $L$ and $R$, but they produce only $R$ gametes.

This mode of reproduction requires hybrids to live sympatrically with the parental species whose genome has been eliminated. In this way hybrids in a L-E system eliminate the $L$ genome thus producing $P$. esculentus when mating with $P$. lessonae, and generating $P$. ridibundus when mating with other hybrids. Usually $P$. ridibundus generated in L-E complexes are inviable due to deleterious mutations accumulating in the clonally transmitted $R$ genome [13-17]. Analogously, in R-E systems there is a tendency during hybrid gametogenesis to eliminate the $R$ genome; as with L-E systems, $P$. lessonae, the offspring of hybrids, are often inviable. 
In natural L-E complexes, the inviability of offspring of $P$. esculentus $\times P$. esculentus matings is evidenced by the absence of adults $P$. ridibundus. Experimental crosses between coexisting hybrids (from localities sampled throughout the range of L-E populations) also show that such offspring are inviable $[6,14,16,17]$. These studies have also revealed that the same hybrid individuals, producing inviable progeny, produce viable progeny when crossed with either parental species or with hybrids from different regions. The lethality of natural hybrid $\times$ hybrid matings is thus neither the result of hybrid sterility nor the inherent consequence of the hemiclonal reproductive mode. Guex et al. present two simple hypotheses, both explaining the observed inviability of P. esculentus $\times$ $P$. esculentus progeny by the load of deleterious mutations on the clonally transmitted R genomes [16]. Quoting from their paper, the hypotheses are "(1) inviability is caused by homozygosity for recessive deleterious mutations at particular gene loci; or (2) inviability is caused by a general deterioration of non-recombining $R$ genomes through Muller's ratchet, reflecting different hemiclonespecific sets of incompletely recessive mutations, which leads to lethality when two such deteriorated $R$ genomes are combined". Their conclusion is that the hypotheses are not mutually exclusive, however there is evidence to support the plausibility of the first hypothesis: Muller's ratchet generates deleterious mutations in relatively random places in the genome, which are then likely to be different in different geographical areas. The study in [16] suggests that, in some cases, single lethal mutations may have the same effect as the accumulation of deleterious ones. However, most studies on P. esculentus fitness, suggest that when in a heterozygous state the effect of deleterious mutation is not significant.

Due to the inviability of $P$. esculentus $\times P$. esculentus offspring, P. esculentus populations cannot survive alone, but must act as a sexual parasite of one of the parental species. This dependency can be avoided only by all-hybrid populations in which the presence of triploid and tetraploid individuals leads to recombination among homolog parental chromosomes [18-23]. This recombination is able to purge, at least partially, deleterious mutations from genomes. thus producing viable offspring of hybrids. Due to its wide distribution, we will consider L-E complexes, in which P. esculentus and P. lessonae coexist. In such a complex, the reproductive pattern is shown in Table 1, where the subscript $y$ indicates the male sexual chromosome.

Table 1 Reproductive pattern of water frogs

\begin{tabular}{lcc}
\hline & $L L$ & $L R$ \\
\hline$L_{y} L$ & $L_{y} L L L$ & $L_{y} R L R$ \\
\cline { 2 - 3 }$L_{y} R$ & $L R$ & $R R$ not viable \\
\hline
\end{tabular}

The Y chromosome determines the sex of frog males and can occur only in the $\mathrm{L}$ genome, due to primary hybridization which involves, due to size constraints, $P$. lessonae males and $P$. ridibundus females. Only one of the three possible matings resulting in viable offspring produces $L L$ genotypes (Table 1 ). This would give an advantage to $P$. esculentus which could outnumber $P$. lessonae and eventually eliminate them. This situation would also eventually result in an extinction of $P$. esculentus which cannot survive without the parental species. In addition to their relative abundance which is promoted by the above reproductive pattern, P. esculentus have other advantages. Although in many cases they show either no differences or intermediate characteristics compared to their parental species [24-27], P. esculentus show behavioural differences $[28,29]$, and, have, by heterosis, a greater fitness than the parental species in certain aspects [13,15,30-36]. The combination of the relative abundance and heterosis should out-compete P. lessonae in L-E complexes. The widespread distribution of L-E complexes, although with different percentages of hybrids, reveals that there are mechanisms which contribute to the stability of such complexes [37-40]. Of these mechanisms, sexual selection seems to be one of the most important. In fact, $P$. esculentus females prefer (either overtly or cryptically) $P$. lessonae males than males of their own species [41-45]. Many mathematical and computational models have studied the influence of sexual selection in the evolution of populations [46-54]. In addition some models have focused on sexual selection in complexes in which some form of clonal reproduction exists [55-57]. The models in [57-59] show how female preference is able to stabilize L-E complexes by counterbalancing both heterosis and the reproductive advantage of $P$. esculentus. Other factors, such as reproductive performance, in conjunction with sexual choice can increase the stability of L-E complexes [60].

Using an individual-based computational model, in this paper we study three problems. The first is how deleterious mutations contribute to the stability of L-E complexes. The second concerns how, in L-E complexes, deleterious mutations can diffuse in the $R$ genomes of the whole $P$. esculentus population. The third is the invasiveness of $P$. ridibundus in L-E complexes.

Regarding the first problem, the aim is to investigate whether deleterious mutations on the $R$ genome contribute, together with female preferences, to the stability of L-E complexes.

As for the diffusion of deleterious mutations in the population, an interesting hypothesis is proposed in [61], in which deleterious mutations can influence female preferences. From the literature we know that females of $P$. esculentus have a strong preference for P. lessonae males. Vorburger et al. in [61] suggest that, of P. esculentus males, 
P. esculentus females may prefer those with mutations on the R genome. Such mutations could make the affected loci on the $\mathrm{R}$ genome dysfunctional, thus producing a more "lessonae-like" genotype.

Finally, regarding the third problem, Vorburger and Reyer in [9] suggest that the introduction of $P$. ridibundus can either provoke the collapse of L-E populations, or result in a replacement by $P$. ridibundus of both $P$. lessonae and $P$. esculentus, leading to a mono-specific population.

In order to gain further insight into the three problems, we attempt to answer three questions.

- Is the role of deleterious mutations necessary for the stability of L-E complexes?

- How can a stable L-E complex be obtained?

- What is the effect of introducing $P$. ridibundus into L-E complexes?

\section{Methods}

\section{The model}

To study the interaction between populations of $P$. lessonae, $P$. esculentus and $P$. ridibundus we developed an individual-based model. To answer the three questions above, we started with a simple model (for the first question) and then extended it step by step (to tackle the second and third questions).

In the simplest model, we consider diploid individuals whose genotype is represented by two chromosome types: $L$ and $R$. Chromosomes $R$ can contain deleterious mutations (represented by $R_{d}$ ), and only chromosomes $L$ can have the sex-determining chromosome $Y$ (represented by $\left.L_{y}\right)$. Thus the possible genotypes are: $L L, L_{y} L, L R, L_{y} R, L R_{d}$, $L_{y} R_{d}, R R, R R_{d}, R_{d} R_{d}$.

The fitness of a genotype $g, \mathcal{F}(g)$, is computed as follows:

$$
\mathcal{F}(g)= \begin{cases}0 & \text { if } g=R_{d} R_{d} \\ e^{-\left(\frac{(1-c(g))^{2}}{2 \sigma^{2}}\right)} & \text { otherwise }\end{cases}
$$

where $\sigma$ is a parameter measuring the strength of the ecological selection (smaller values of $\sigma$ correspond to a stronger selection). In the simulations we use two different values for $\sigma, \sigma=0.4$, which corresponds to a hard environment, and $\sigma=0.6$, which corresponds to a weaker selection.

Function $c(g)$, is the chromosomes fitness, defined as follows:

$$
c(g)= \begin{cases}1 & \text { if } g \in\left\{L R, L_{y} R, L R_{d}, L_{y} R_{d}\right\} \\ 1-\delta_{h} & \text { if } g \in\left\{L L, L_{y} L\right\} \\ 1-\delta_{h}-\delta_{e} & \text { if } g \in\left\{R R, R R_{d}\right\}\end{cases}
$$

where $\delta_{h}$ and $\delta_{e}$ describe the fitness decrement associated with homozygous genotypes (which do not gain from heterosis), and $P$. ridibundus genotypes, respectively. The use of a further decrement, $\delta_{e}$, in the chromosome fitness of
P. ridibundus, derives from the fact that L-E complexes usually live in pools and marshes, where $P$. ridibundus are less fit. In the following sections, we use $\delta_{h}=0.2$ and $\delta_{e}$ will assume the values $0.0,0.2$, and $0.4 . \delta_{e}=$ 0.0 means that $P$. ridibundus have the same fitness as $P$. lessonae (i.e. the environment includes niches for both species), while $\delta_{e}=0.4$ represents the fact that $P$. ridibundus are strongly disadvantaged compared to $P$. lessonae (i.e. the environment consists of a typical $P$. lessonae habitat).

We consider that the populations have a reproductive season each year. During this season all the females mate. Female sexual choice is implemented by a best-of- $n$ selection procedure of males $[52,62]$, i.e. a female mates with the most preferred of $n$ randomly chosen males in the population. The best-of- $n$ procedure, which is a usual computational method to take into account female preferences, can be described as follows. Consider a population of males of $k$ different types, $m_{1}, m_{2}, \ldots m_{k}$, with numbers of individuals $N_{m_{1}}, N_{m_{2}}, \ldots N_{m_{k}}$, respectively, and a total male population $N_{m}=N_{m_{1}}+N_{m_{2}}+\ldots+N_{m_{k}}$. Consider a female of type $f$ with different preference values for $k$ kinds of males, $p_{m_{1}}^{f}, p_{m_{2}}^{f}, \ldots, p_{m_{k}}^{f}$, such that $p_{m_{1}}^{f}<p_{m_{2}}^{f}<\ldots<p_{m_{k}}^{f}$. According to the best-of- $n$ procedure, the female chooses the best (following her preferences) of the $n$ ones randomly taken from the population of all males. Thus the probability, $\operatorname{prob}_{m_{i}}^{f}$, of a female of type $f$, choosing a male of type $m_{i}, i \in[0, k]$, is given by the probability of randomly taking no $m_{j}$ males, with $p_{m_{j}}^{f}>p_{m_{i}}^{f}$, times the probability of having at least one $m_{i}$ male of the taken ones. Using the hypergeometric probability distribution, $\operatorname{prob}_{m_{i}}^{f}$ is given by the following formula.

$\operatorname{prob}_{m_{i}}^{f}=\frac{\left(\begin{array}{c}N_{m_{1}}+N_{m_{2}}+\ldots+N_{m_{i}} \\ n\end{array}\right)}{\left(\begin{array}{c}N_{m} \\ n\end{array}\right)}\left(\sum_{i=1}^{n} \frac{\left(\begin{array}{c}N_{m_{i}} \\ i\end{array}\right)\left(\begin{array}{c}N_{m_{1}}+N_{m_{2}}+\ldots+N_{m_{i-1}} \\ n-i\end{array}\right)}{\left(\begin{array}{c}N_{m_{1}}+N_{m_{2}}+\ldots+N_{m_{i}} \\ n\end{array}\right)}\right)$

Note that the greater $n$ is, the greater the strength of the female preference. Increasing the $n$ value will lead to a female choosing from a greater number of males, thus mimicking the behaviour of a more discriminating female. In order to obtain stable complexes, we assume a species-specific female preference, in particular, following the studies in $[59,60]$, we assign a stronger preference to females of the parental species than the hybrid females. P. esculentus females have the same behaviour as $P$. lessonae, thus competing for the same kind of males. Likewise, $P$. ridibundus females prefer more "ridibunduslike" males. Hereafter we call "lessonae preference" this kind of female preference, because $P$. lessonae males are the most preferred. The number of $n$ candidates, which each female chooses from, is set to 30,15 , and 30 for the $P$. lessonae, $P$. esculentus, and P. ridibundus females, 
respectively. Choosing from among 30 candidates has a biological flavour. If males are distributed in the environment with a density of one male per square meter, each female must swim in a circle of 10 meters of diameter in order to check out 30 males, a distance which is reasonable for a frog. In [57-59] it is shown that stable populations are only found when the preference of $P$. lessonae females is greater than the preference of $P$. esculentus females. In these papers it is shown that, under the above assumption, many different values of female preference lead to stable complexes. We have performed many simulations by leaving the value of $n$ for $P$. lessonae and $P$. ridibundus unmodified, and by varying the value of $n$ for P. esculentus. We have found that if the ratio of the value of P. esculentus to the value of the parental species belongs to the interval $[0.03,0.7]$ we obtain stable complexes, when P. ridibundus are inviable. This result is analogous to the ones in [57-59]. Because different values in the interval $[0.03,0.7]$ affect only the percentage of hybrid frogs in the final stable population, the choice of $n$ does not change the overall dynamics of the population. For this reason we use the non-extreme value 0.5 .

Offsprings genotypes are obtained from the gamete combination of the parents.

The reproductive season is followed by a viability selection. During this phase the probability that an individual of genotype $g$ survives, $p_{\text {surv }}(g)$, is given by a slight modification of the Beverton-Holt model: [63-68]:

$$
p_{\text {surv }}(g)=\frac{1}{1+b \phi \frac{N}{\mathcal{K}(g)}}
$$

where $b$ is the average number of offspring for females that can reach the stage of adults, $\phi$ is the percentage of females in the population, $N$ is the number of individuals in the population competing for the resources, and $\mathcal{K}(g)$ is the carrying capacity associated with the genotype g. $\mathcal{K}(g)$ is given by $\mathcal{F}(g) \mathcal{K}_{0}$ where $\mathcal{K}_{0}$ is the maximum carrying capacity of the environment. In all our simulations we assume $b=6$ and $\mathcal{K}_{0}=3000$. The standard Beverton-Holt model is modified due to the fact that we consider overlapping generations and we apply the viability selection based on survival probability, not only to young tadpoles but to all the individuals in the population. The simplest model is used to answer the first question by performing both simulations in which all $R$ genomes carry deleterious mutations and simulations in which all $R$ genomes are free from deleterious mutations.

To answer the second question, "How can a stable L-E complex be obtained?", we simulate the diffusion of deleterious mutations in the population, starting with an L-E complex, composed by $P$. lessonae, in which there are only a few $P$. esculentus individuals (without mutations on the $R$ genome). We consider a mutation rate, $\mu$, which gives the probability of adding a new deleterious mutation on the $R$ genome of an offspring (in the simulations $\mu$ is set both to $10^{-4}$ and to $10^{-5}$ ). We consider different "stages" in the accumulation of mutations in the $R$ genome. For the sake of simplicity we consider only three stages: $R, R_{d 1}$, and $R_{d} . R$ is the genome without mutations, $R_{d 1}$ is the genome with a non lethal accumulation of mutations, and, as before, $R_{d}$ is the final stage of accumulation (lethal in homozygous individuals). With this scenario we have $P$. ridibundus females with the following possible genotypes (in order of decreasing fitness): $R R, R R_{d 1}, R R_{d}, R_{d 1} R_{d 1}, R_{d 1} R_{d}, R_{d} R_{d}$, where $R_{d} R_{d}$ is the only lethal genotype. The fitness decrease of each genotype with respect to the previous one is given by $\delta_{m}$. In the simulations we set $\delta_{m}=0.04$. In this scenario, following [61], we assume that $P$. lessonae and $P$. ridibundus females have a strong preference for males of their own species, while of $P$. esculentus males, females prefer males with a more "lessonae-like" genotype (males with mutations on the $R$ genotype). We call this kind of female preference "lessonae-like preference". We have $P$. esculentus males with the following genotype: $L_{y} R, L_{y} R_{d 1}, L_{y} R_{d}$, which, according to the "lessonae-like preference", are in order of increasing preference by the female.

Finally, to answer the third question, "What is the effect of introducing P. ridibundus into L-E complexes?", we need to simulate the effect of the introduction of $P$. ridibundus males and females in an L-E complex. In these simulations we consider both $R$ genomes without mutations; this is because we assume the absence of the Muller ratchet in the (sexually reproducing) introduced $P$. ridibundus and $R_{d}$ genomes generated by the stable L-E complex. The further extension we consider is the possibility of having $P$. ridibundus males, i.e. the possibility of having the $Y$ chromosome on $R$ genomes as well: $R_{y}$ and $R_{y d}$.

We introduced a limit for the lifespan of individuals, thus all individuals exceeding 10 years of age are removed from the population. Removing old frogs from the system avoids that extremely fit individuals survive indefinitely because the viability selection is not able to remove them. This situation can easily happen in models with overlapping generations which do not consider deaths due to aging.

The parameters used in the model, with their meaning and values, are reported in Table 2.

\section{Implementation}

The process was formalize with CLS [69-75] and then implemented in $\mathrm{C}++$ language using Microsoft Visual Studio 2010. Each simulation runs for 2000 iterations (more when necessary) with a carrying capacity of 3000 individuals. A single simulation takes nearly 10sec on a worstation equipped with Intel i5 $3.2 \mathrm{Ghz}$ processor and 8GB RAM. 
Table 2 Parameters used in the model

\begin{tabular}{ll}
\hline$\sigma$ & Selection strength \\
$\delta_{h}$ & Fitness decrease due to homozygosity \\
$\delta_{e}$ & Fitness decrease for environmental reasons \\
$\delta_{m}$ & Fitness decrease for each step of mutation accumulation \\
$n$ & Number of attempts per female in choosing males, P. lessonae, P. esculentus, P. ridibundus \\
$b$ & Number of surviving tadpoles for each female \\
$\mathcal{K}_{0}$ & Environmental carrying capacity \\
$\mu$ & mutation rate
\end{tabular}

\section{Results}

Is the role of deleterious mutations crucial for the stability of L-E complexes?

The first step in studying the role of deleterious mutations for the stability of L-E complexes is to consider an initial population composed of $P$. lessonae frogs and small percentages of $P$. esculentus: $5 \%, 10 \%$, and $20 \%$, respectively. Note that an initial situation with a large number of $P$. lessonae individuals favours the stabilization of the complex (there is no possibility of an early collapse due to the greater fitness of $P$. esculentus). We assume that all $P$. esculentus individuals carry the deleterious mutations on the $R$ genome, that is $P$. ridibundus females are not viable and they do not appear in the population. We assume the "lessonae preference" for females, based on the values 30,15 , and 30 for the best-of- $n$ procedure for the three species, as described in the previous section. Finally we consider $\delta_{h}=0.2$. We perform simulations with $\sigma=0.4$ and $\sigma=0.6$. For each combination of parameters $\sigma$ and $\delta_{e}$ we performed 100 simulations, the possible outcomes of which are either a stable L-E complex or the collapse of the whole population. In all the simulations the populations evolve towards a stable L-E complex, following a typical population composition pattern (Figure 1).

The result of these simulations is not surprising. Essentially the results are in accordance with those in $[58,59]$, showing that female preference is a strong stabilizing force for L-E complexes.
In order to investigate the role of deleterious mutations in the stability of L-E complexes, we consider the same parameters as the previous simulations, but we remove the deleterious mutations from all the $R$ genomes of the initial population. In addition, we set $\delta_{e}$ to 0.2 and 0.4 , that is we consider that all $P$. ridibundus born from hybrids are always disadvantaged compared to $P$. lessonae and $P$. esculentus. We also set the mutation rate $\mu$ equal to 0 , in order to prevent deleterious mutations, considering only a "mutation-free" population. We can observe that with all the parameter combinations and the initial percentages of $P$. esculentus, in all the simulations the population eventually collapses. If viable $P$. ridibundus females are produced, the reproductive pattern becomes as depicted in Table 3. The table highlights that this reproductive pattern generates a numerical disadvantage for P. lessonae, the population of which decreases. The decrease in the $P$. lessonae population has, as a consequence, a decrease in produced $L$ gametes, which, in turn, results in a higher production of $P$. ridibundus. Thus the population of $P$. ridibundus females grows and eventually out-competes the other species, despite the weaker fitness of $P$. ridibundus females compared both to P. esculentus $\left(\delta_{h}=0.2\right)$ and to $P$. lessonae $\left(\delta_{e}=0.2\right.$ and $\left.\delta_{e}=0.4\right)$, see Figure 2 . Of course a population of only $P$. ridibundus females cannot survive.

Note that the higher the percentage of P. esculentus in the initial population, the smaller the number of generations before the collapse. By varying either the strength of

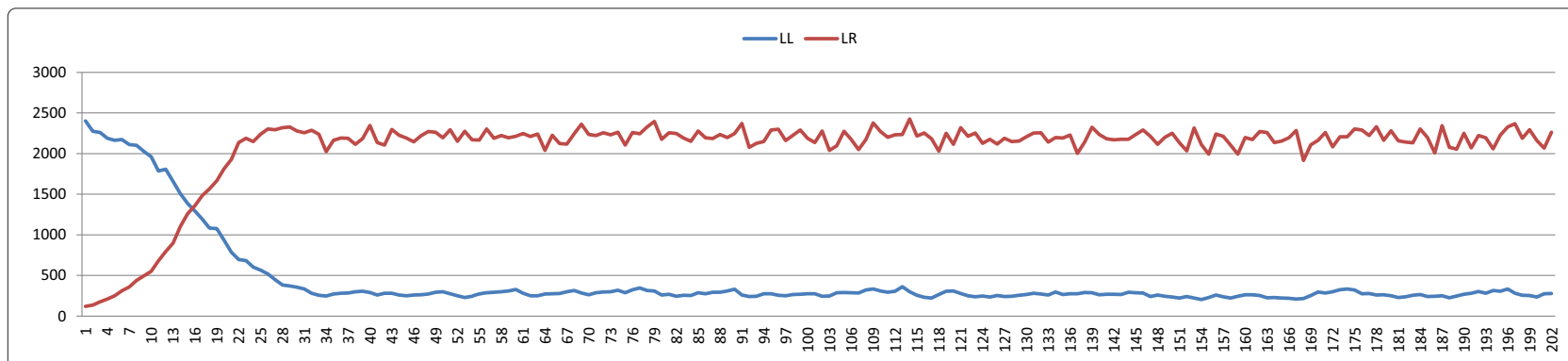

Figure 1 Results with an initial population composed of $P$. lessonae frogs and a percentage of $5 \% P$. esculentus carrying deleterious mutations. $\sigma=0.4, \mu=0$. 
Table 3 Reproductive pattern of water frogs without deleterious mutations

\begin{tabular}{lccc}
\hline & $L L$ & $L R$ & $R R$ \\
\hline$L_{y} L$ & $L_{y} L L L$ & $L_{y} R L R$ & $L_{y} R \quad L R$ \\
\cline { 2 - 4 }$L_{y} R$ & $L R$ & $R R$ & $R R$ \\
\hline
\end{tabular}

female preferences or the strength of ecological selection, we obtain different values for the number of generations before the collapse, but an evolution towards collapse remains the overall trend of the system. Even when $P$. ridibundus are at a serious disadvantage, $\delta_{e}=0.4, R R$ females are able to compromise the stability of L-E complexes. Of course, we amplify this effect by decreasing $\delta_{e}$, thus we do not show the population dynamics with $\delta_{e}=0.0$. In this case, the point of collapse is reached very quickly.

\section{How can a stable L-E complex be obtained?}

In this section we study the effect of both "lessonae preference" and "lessonae-like preference" of P. esculentus and $P$. lessonae females in the diffusion of deleterious mutations. We set the mutation rate, $\mu$, either to $10^{-4}$ or to $10^{-5}$. We consider three possible stages of deleterious mutation accumulation in each $R$ genome $\left(R, R_{d 1}\right.$, and $R_{d}$ ), thus any mutation event determines the passage from one stage to the next. We start the simulations with two different initial populations. The consistency of the initial $P$. lessonae population is the same in all the simulations, 2700 individuals, but the number of $P$. esculentus individuals is set, initially, either to 10 or 100 individuals. We also perform simulations with two values for $\delta_{e}$, which lead to a decrease in fitness of mutationfree $P$. ridibundus compared to $P$. lessonae. We set $\delta_{e}$ to either 0.2 or 0.4 , i.e. we consider that the environment is either weakly penalizing for $P$. ridibundus or is a typical $P$. lessonae habitat, which is not suitable for $P$. ridibundus frogs. In addition, any further mutation accumulation on the $R$ genomes of $P$. ridibundus decreases their fitness by $\delta_{m}=0.4$.
Firstly, we consider the "lessonae preference". According to this preference pattern, $P$. esculentus and $P$. lessonae females prefer $P$. lessonae males, and, do not choose among $P$. esculentus males. The results of the simulations show that in our model both with 10 and with 100 P. esculentus mutation-free individuals in the initial population, and with any value for $\delta_{e}$ and $\sigma$, the lethal deleterious mutation diffuses slowly. This slow diffusion is not able to prevent the production of a sufficient number of viable $P$. ridibundus females, which leads to the collapse of the population with all possible parameter values. Figure 3 shows a typical dynamic of the population while Figure 4 shows the diffusion of mutations in the $R$ genome of $P$. esculentus. The results of the simulations with $\sigma=0.4$ and $\mu=10^{-4}$ are shown in Table 4.

Secondly, we consider the "lessonae-like preference". According to this preference pattern $P$. esculentus and $P$. lessonae females prefer $P$. lessonae males, and, of $P$. esculentus males, they prefer those with a greater accumulation of deleterious mutations. The results of simulations confirm that female choice can lead to the diffusion of deleterious mutations in the $P$. esculentus genomes if those mutations silence $P$. ridibundus traits and result in more "lessonae-like" P. esculentus males. In this scenario, stable complexes can be obtained with $\delta_{e}=0.4$, while a higher fitness of $P$. ridibundus leads to the extinction of the population (Table 5). Starting with mutation-free $P$. esculentus individuals, the diffusion of mutations passes through different stages of mutation accumulations. The pattern of mutation diffusion is that mutation rates contribute to deleterious mutations, while the "lessonae-like preference" favours the production of offspring of $P$. esculentus males with a stronger mutation accumulation on their $R$ genome. In the progression of mutation accumulation, $R R$ genotypes gets more and more inviable while $L R$ males become more and more attractive. When $\delta_{e}=$ 0.4 , Figure 5 shows a typical dynamic of the population, while Figure 6 shows the diffusion of mutations in the $R$ genome of $P$. esculentus. The results of the simulations with $\sigma=0.4$ and $\mu=10^{-4}$ are shown in Table 5 .

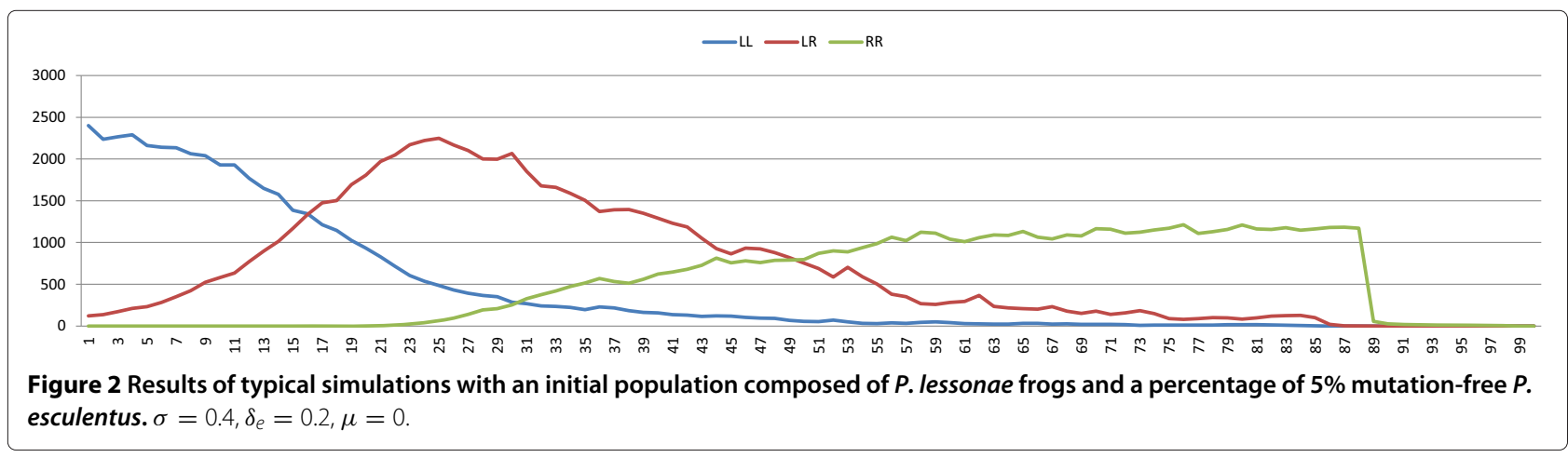




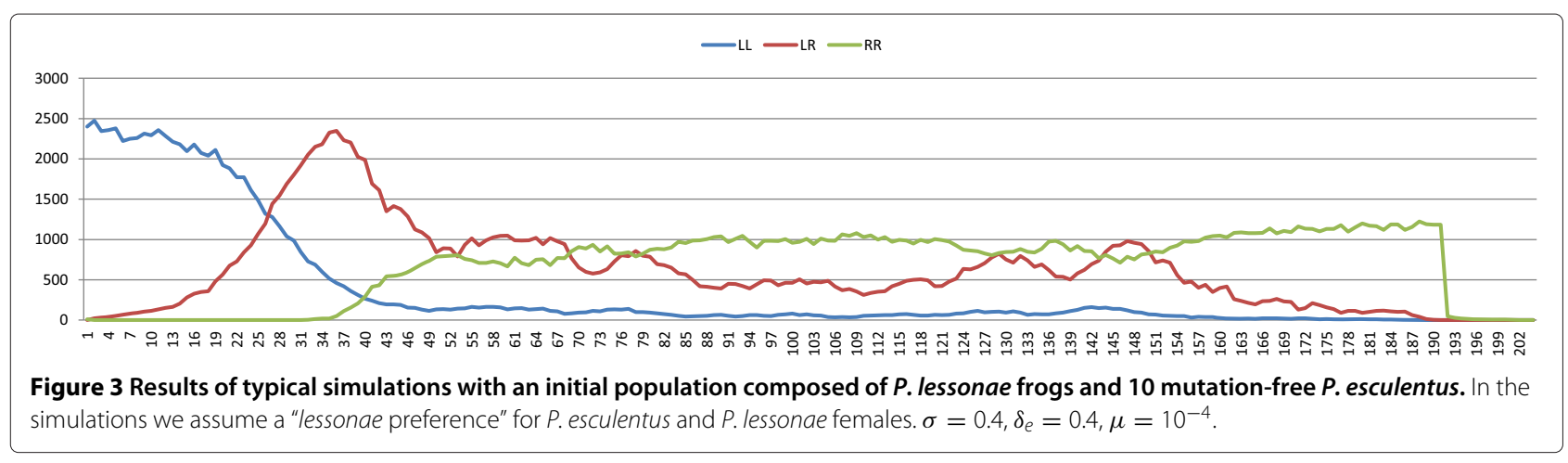

What is the effect of the introduction of $P$. ridibundus in L-E complexes?

In this section we analyze the effect of introducing $P$. ridibundus into an L-E complex. This scenario really happens in natural environments due to the importation in Western Europe of $P$. ridibundus for commercial purposes.

In order to study the effect of the translocation of $P$. ridibundus, we performed simulations by varying the fitness of the introduced frogs $\left(\delta_{e}=0.0,0.2,0.4\right) . \delta_{e}=0.0$ means that the environment does not put $P$. ridibundus at a disadvantage with respect to $P$. lessonae. In these simulations we consider a strong selection strength, $\sigma=0.4$.

We study the effect of introducing, in a stable L-E complex, a percentage of both $5 \%$ and $10 \%$ of $P$. ridibundus, males and females. We consider three different situations: i) $P$. ridibundus are introduced into the typical environment for $P$. lessonae $\left(\delta_{e}=0.4\right)$, ii) $P$. ridibundus are introduced into a mixed (lake/marsh) environment $\left(\delta_{e}=0.2\right)$, and iii) $P$. ridibundus are released into an environment that is fit for them (possibly close to resident frogs) $\left(\delta_{e}=0.0\right)$. We have four possible outcomes: stable L-E systems, stable L-E-R systems, stable $P$. ridibundus populations, and the collapse of the population (Table 6, Figures 7, 8, and $9)$. In the figures we show the dynamics for $\sigma=0.4$. For $\sigma=0.6$ we obtain analogous evolutions.

If the fitness of $P$. ridibundus is equal to the fitness of $P$. lessonae $\left(\delta_{e}=0.0\right)$, in most cases the population becomes a mono-specific population of $P$. ridibundus. Note that there are many cases in which the three species coexist at the end of the simulations, which we discuss explicitly in the following section. If the fitness of $P$. ridibundus decreases $\left(\delta_{e}=0.2\right)$, the introduced frogs do not survive for long. However, before their extinction $P$. ridibundus can mate with $P$. lessonae and P. esculentus, thus introducing mutation-free $R$ genomes into the hybrid population. At this point, viable $P$. ridibundus females born from matings between hybrids lead the population to collapse. Finally, when the fitness of $P$. ridibundus is very low $\left(\delta_{e}=\right.$ $0.4), P$. ridibundus frogs are immediately expelled from the system.

\section{Discussion}

From the results of the previous section we can deduce the overall dynamics of L-E complexes with viable $P$. ridibundus females. In general, the presence of viable $P$. ridibundus females significantly changes the reproductive outcome of L-E complexes, and the generation of offspring becomes as depicted in Table 3. For the sake of simplicity let us consider hypothetical complexes in which the number of females is the same for the three species. For such populations the production of P. lessonae offspring passes from $33.33 \%$ in stable L-E complexes (recall that in such complexes $P$. ridibundus are inviable and do not survive) to $16.66 \%$ in complexes where $P$. ridibundus

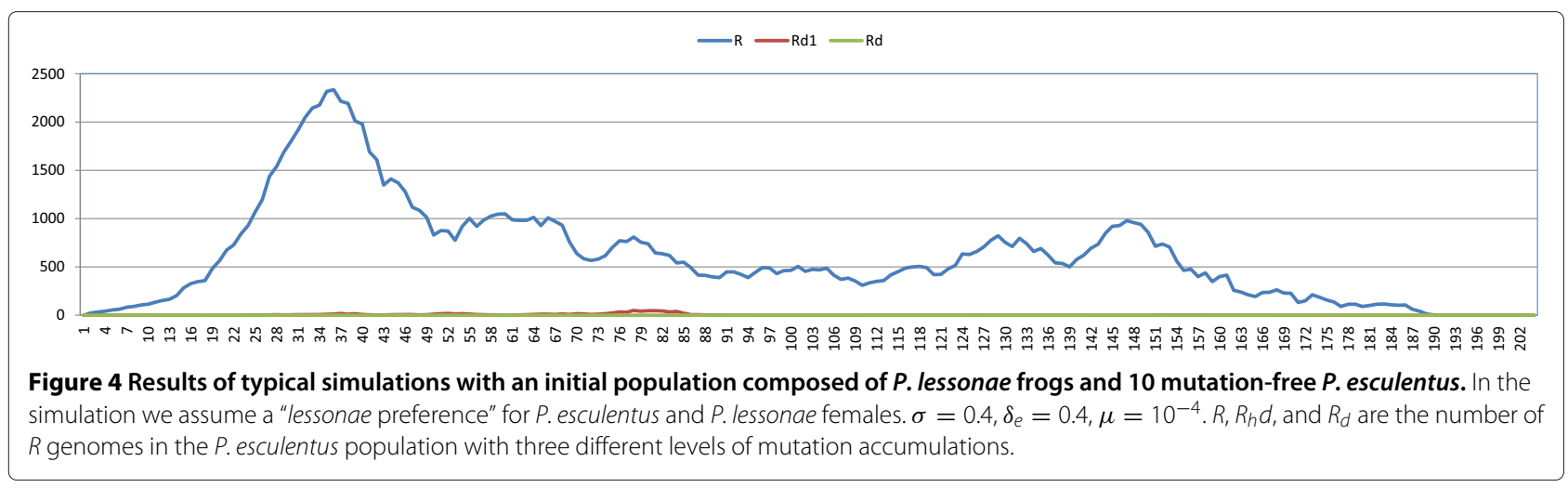


Table 4 Outcomes of 100 simulations with an initial $P$. esculentus population of 10 and 100 individuals without deleterious mutations on the $R$ genome

\begin{tabular}{|c|c|c|}
\hline \multicolumn{3}{|c|}{ a) $\delta_{e}=0.2$} \\
\hline Initial P. esculentus pop. & 10 & 100 \\
\hline Stable L-E system & 0 & 0 \\
\hline LL population & 0 & 0 \\
\hline Collapse & 100 & 100 \\
\hline \multicolumn{3}{|c|}{ b) $\delta_{e}=0.4$} \\
\hline Initial P. esculentus pop. & 10 & 100 \\
\hline Stable L-E system & 0 & 0 \\
\hline LL population & 0 & 0 \\
\hline Collapse & 100 & 100 \\
\hline
\end{tabular}

In the simulations we assume a "lessonae preference" for $P$. esculentus and $P$. lessonae females. The parameters are: $\sigma=0.4, \mu=10^{-4}$.

survive. Thus the viability of $P$. ridibundus decreases the relative abundance of $P$. lessonae offspring. The decrease in the relative production of $P$. lessonae offspring leads to a decrease in $P$. lessonae adults in the future. This, in turn, causes a decrease in the production of $L$ gametes, which are produced only by $P$. lessonae frogs. This process, if not stopped by some external reasons, results in a trend towards the extinction of $P$. lessonae. A population composed only of $P$. esculentus individuals and $P$. ridibundus females cannot survive, because no gametes with the $Y$ chromosome can be generated.

The discussion which follows, regarding the three questions mentioned previously, is based on the trend towards extinction mentioned above, modulated for example by the accumulation of mutations, or the introduction of viable $P$. ridibundus males.

Table 5 Outcomes of 100 simulations with an initial $P$. esculentus population of 10 and 100 individuals without deleterious mutations on the $R$ genome

\begin{tabular}{|c|c|c|}
\hline \multicolumn{3}{|c|}{ a) $\delta_{e}=0.2$} \\
\hline Initial P. esculentus pop. & 10 & 100 \\
\hline Stable L-E system & 0 & 0 \\
\hline LL population & 0 & 0 \\
\hline Collapse & 100 & 100 \\
\hline \multicolumn{3}{|c|}{ b) $\delta_{e}=0.4$} \\
\hline Initial P. esculentus pop. & 10 & 100 \\
\hline Stable L-E system & 76 & 73 \\
\hline LL population & 1 & 0 \\
\hline Collapse & 23 & 27 \\
\hline
\end{tabular}

In the simulations we assume a "lessonae-like preference" for $P$. esculentus and $P$. lessonae females. The parameters are: $\sigma=0.4, \mu=10^{-4}$.

\section{Deleterious mutations are necessary for the stability of L-E complexes}

We showed in Section 'Is the role of deleterious mutations crucial for the stability of L-E complexes?' that by using the "lessonae preference", we essentially obtain the same results as $[58,59]$. If there are no viable $P$. ridibundus offspring, the system evolves towards stability regardless of the strength of the selection. The same complexes, with the same values of female preferences, but without deleterious mutations on $R$ genomes will collapse irrespectively both of the selection strength and the fitness of viable $P$. ridibundus. In the dynamics of the population towards collapse, there are roughly three phases. In the first phase, the effect of sexual selection and the abundance of $P$. lessonae males maintains a low number of $P$. ridibundus offspring. Although no mutations are present in the $P$. esculentus genome, a very few $P$. ridibundus females are generated because mating between hybrids is rare, due to female preferences. In the second phase, the number of hybrids increases because of their fitness as a result of heterosis, while the number of $P$. lessonae decreases. In this phase the increased number of hybrids facilitates mating which thereby produces viable $P$. ridibundus females. In the third phase, $P$. ridibundus females act as sexual parasites for hybrids, and their number grows because of $P$. esculentus $\times P$. esculentus and $P$. esculentus $\times P$. ridibundus matings. Note that these matings produce only $P$. ridibundus females. Viable $P$. ridibundus females will mate, preferably, with $P$. esculentus males (which have a more "ridibundus phenotype") producing a bigger population of ridibundus females for any further generation. In the model we do not consider male frogs as a limiting factor for reproduction, that is one male is able to fertilize the eggs of a unlimited number of females. We consider also that males will not make any specific choice of females [45]. The number of $P$. esculentus decreases because of the reduced number of $P$. lessonae. This phase ends with a population of all $P$. ridibundus females which quickly collapses (Figure 2).

Consequently, if stability is maintained by female preferences, collapse only can be prevented if the initial population of $P$. esculentus is affected by deleterious mutations on the $R$ genomes, which prevents the birth of viable $P$. ridibundus. Thus we can conclude that, in a system in which the parameters used for the stability are essentially female preferences and viability of $P$. ridibundus, deleterious mutations are necessary for the stability of the complex. These results help to clarify why natural L-E complexes generating viable $P$. ridibundus are extremely rare, and in most cases the percentage of viable P. ridibun$d u s$ is not significant [15]. It is difficult (perhaps impossible) for L-E complexes to persist if they generate viable $P$. ridibundus. Starting with an initial population in which all $P$. esculentus frogs carry deleterious mutations, the 


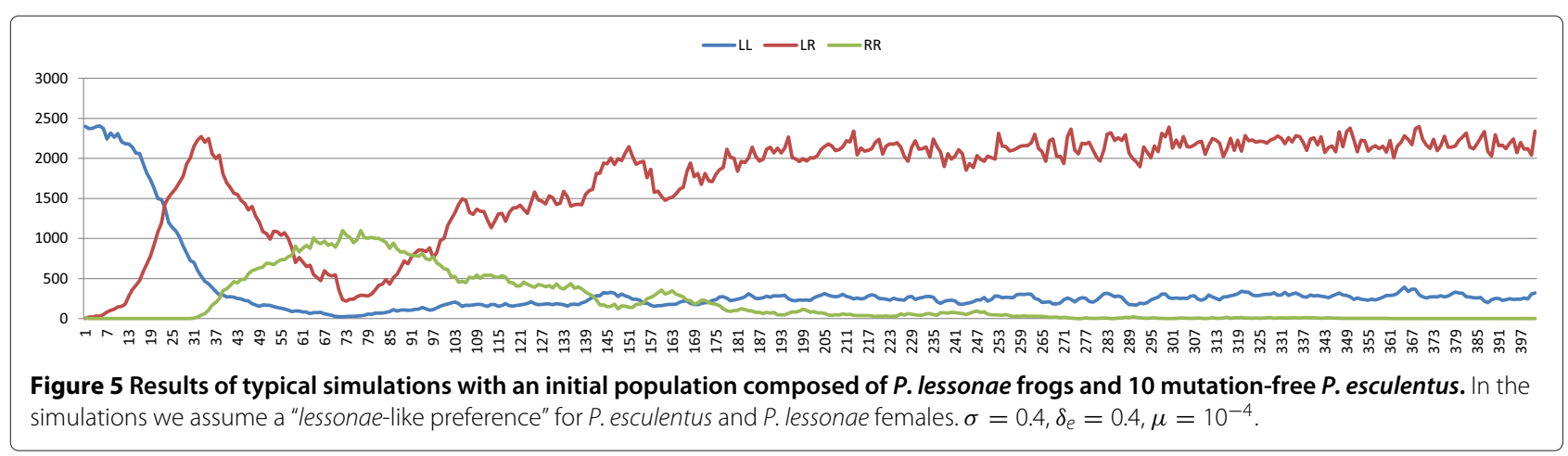

complex evolves towards a stable configuration (Figure 1). The possible collapse of the population occurs only if $P$. esculentus out-compete $P$. lessonae, however this evolution seldom takes place because of the large number of $P$. lessonae in the initial population. The results show that, with the same selection strength, L-E complexes evolve towards the same percentages of the two frog species, whatever the initial percentages.

Our results regarding the stability of L-E complexes both with deleterious mutations in all $R$ genomes and with a "lessonae preference" are similar to those in [57-59]. We show that deleterious mutations strongly influence the stability of L-E complexes. Thus deleterious mutations are not only a secondary consequence of Muller's ratchet but they have an important role in the stability of complexes. In this paper we highlight that, if we consider both heterosis and females preferences as the only stabilizing forces of L-E complexes, the lack of deleterious mutations drives such populations to collapse. Thus neither female preferences nor deleterious mutations are sufficient to maintain the stability of L-E complexes however, in this scenario, each is necessary for stability.

\section{Female preference can contribute to obtaining stable L-E complexes}

The above discussion highlights the important role of deleterious mutations in stable L-E complexes. But how can stable L-E complexes be obtained?
Our results show that, in order to reach stable L-E populations, there must be forces that drive the diffusion of deleterious mutations. Even with a fast mutation rate, $10^{-4}$, Muller's ratchet alone is not sufficient for diffusing the deleterious mutations in the population. The "lessonae preference" does not allow $P$. lessonae and $P$. esculentus females to choose from among $P$. esculentus males. Thus the diffusion of deleterious mutation among $P$. esculentus individuals and $P$. ridibundus females is not guided by female preferences, but only by the mutation rate (essentially by Muller's ratchet). In all our simulations this diffusion turns out to be very slow, thus viable $P$. ridibundus females are generated before Muller's ratchet accumulates lethal mutations on all $R$ genomes. This intermediate phase, with a sufficient number of viable $P$. ridibundus females, is responsible for the collapse of the whole system.

Selecting $R$ genomes with a higher mutation accumulation is accelerated by the "lessonae-like preference". In this case the production of offspring with greater mutation accumulation on the $R$ genome is favoured, and consequently the production of fit $P$. ridibundus females is lowered. To understand this process we need to consider that mutation accumulation on $R$ genomes decreases the fitness of $P$. ridibundus females, but it does not affect the fitness of $P$. esculentus in which dysfunctional $R$ genomes are counterbalanced by "healthy" $L$ genomes.

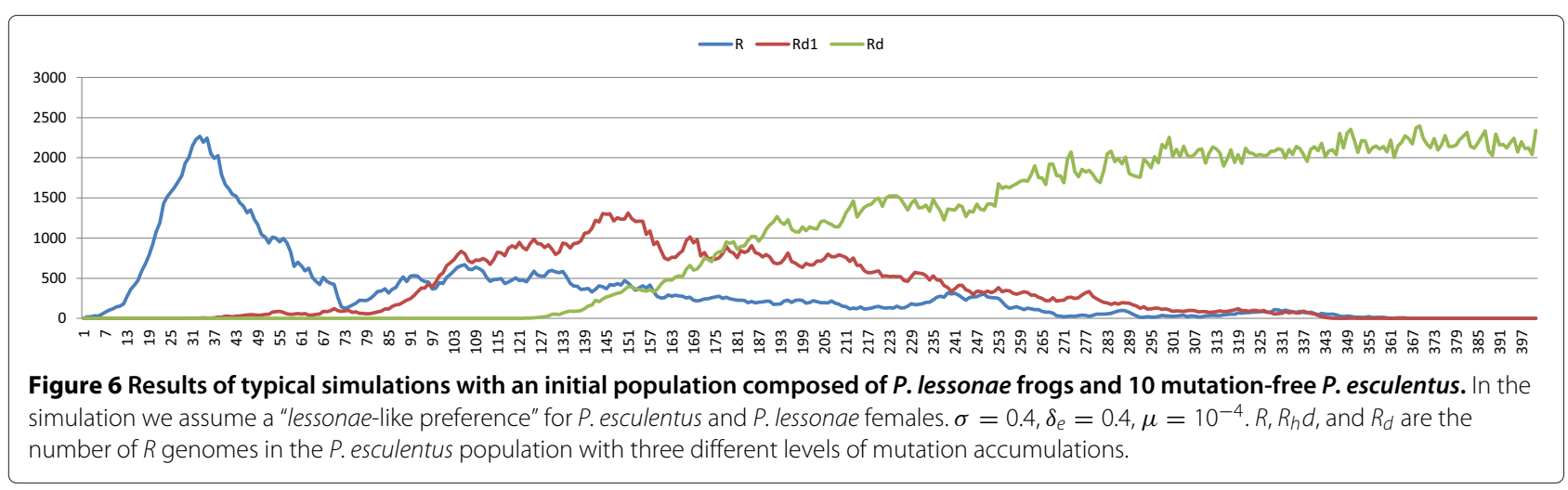


Table 6 Outcomes of 100 simulations in which in a stable L-E complex a percentage of $5 \%$ of $P$. ridibundus, males and females, are introduced

\begin{tabular}{rccc}
\hline & $\boldsymbol{\delta}_{\boldsymbol{e}} \mathbf{=} \mathbf{0 . 0}$ & $\boldsymbol{\delta}_{\boldsymbol{e}}=\mathbf{0 . 2}$ & $\boldsymbol{\delta}_{\boldsymbol{e}} \mathbf{=} \mathbf{0 . 4}$ \\
\hline Stable L-E system & 0 & 46 & 100 \\
\hline Stable L-E-R system & 32 & 0 & 0 \\
\hline Stable P. ridibundus population & 39 & 0 & 0 \\
\hline Collapse & 29 & 54 & 0
\end{tabular}

The three columns correspond to different values of $\delta_{e}, 0.0,0.2$, and 0.4, respectively. $\sigma=0.4, \mu=0$.

Another important point is that a significant parameter in the diffusion of deleterious mutations is the fitness of $P$. ridibundus to the environment. If this fitness is too high, too many viable $P$. ridibundus females are produced before significant mutation accumulations. We know that a high number of such viable females will lead the population to collapse.

For computational purposes we have considered only three stages of mutation accumulation on the $R$ genomes. This is an approximation of the Muller's ratchet which, in most cases, operates through a huge number of mutations. We approximate the Muller's ratchet by decreasing the mutation rate so that a mutation in the model corresponds to many mutations in real genomes. Following the estimation in [76], we assume that, in an eukaryote organism, the mutation rate in a whole genome during sexual reproduction is in the interval $\left[3 \times 10^{-2}, 9 \times 10^{-1}\right]$. Many of these mutations are either not significant or not deleterious. Values of the mutation rate in the interval $\left[10^{-5}, 10^{-4}\right]$, used in our model, take both the above considerations into account.

Our study differs significantly with the results of other authors with regard to the diffusion of mutations. The models in [58-60] provide an extensive insight into the reasons for the stability of L-E complexes starting from the assumption that deleterious mutations are present in all the $R$ genomes in the population. Our model builds on the previous ones by assuming sexual choices in the populations. However, it differs by considering a population in which deleterious mutations are not present, but are generated according to a mutation rate. In addition, only when this accumulation reaches a given threshold does it become lethal. This leads us to conclude that sexual selection not only stabilizes the complexes, but can also force mutation diffusion.

Note that our simulations do not enable us to prove the hypothesis suggested in [61]. Computational and mathematical models, without subsequent experimental support, can only be used to rule out incorrect hypotheses - they cannot prove correct ones. Computational and mathematical models can only state that a hypothesis is plausible. In the case of L-E complexes, the stabilization period is so long that no real experiment can support a hypothesis on its stabilization, however our model suggests that the hypothesis in [61] regarding female preference, could plausibly lead to stable L-E complexes.

\section{Invasion of translocated $P$. ridibundus}

Another point that we study with our model is the consequence of introducing $P$. ridibundus into stable L-E complexes. $P$. ridibundus can mate both with $P$. esculentus, producing $P$. ridibundus, and with $P$. lessonae (primary hybridization), producing $P$. esculentus. Primary hybrids can have low fertility rates [77], thus their contribution to the dynamics of the population is low. In our model we take account of this low contribution by decreasing the possibility of producing primary hybrids. This is done by setting the female preferences of $P$. ridibundus in a way that $P$. lessonae males are seldom chosen (the value of $n$, in the best-of- $n$ procedure, is set to 30). On the other hand, the preference of $P$. lessonae females is mainly for males of their own species. We assign the same fitness both to the introduced $P$. ridibundus and to those generated by matings of $P$. ridibundus with $P$. esculentus. This is in accordance with the semi-natural experiments in [17]. However, in some simulations we use a $P$. ridibundus fitness, which is lower than the fitness of the

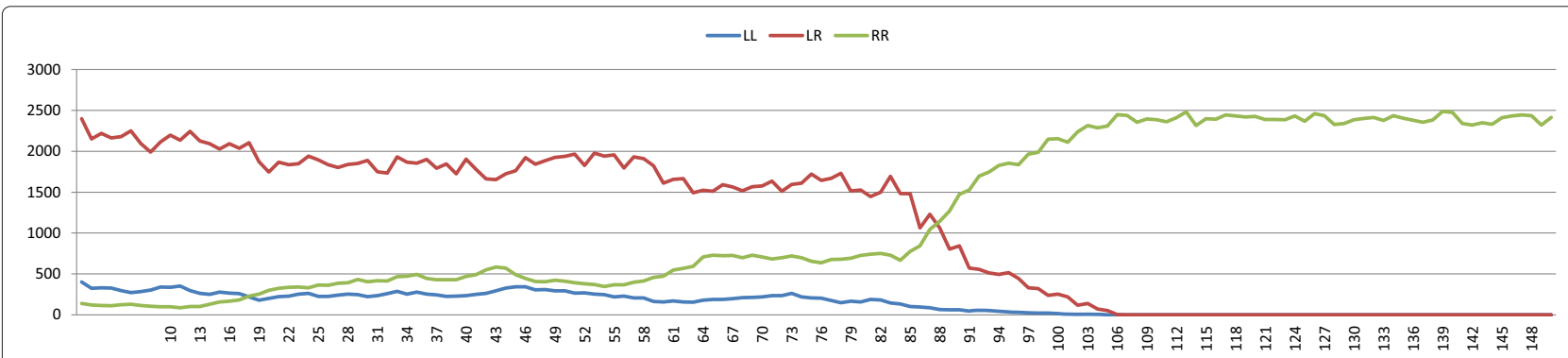

Figure 7 Results of typical simulations with an initial stable L-E population in which a percentage of $5 \%$ of $P$. ridibundus, males and females, are introduced. $\sigma=0.4, \delta_{e}=0.0, \mu=0$. 


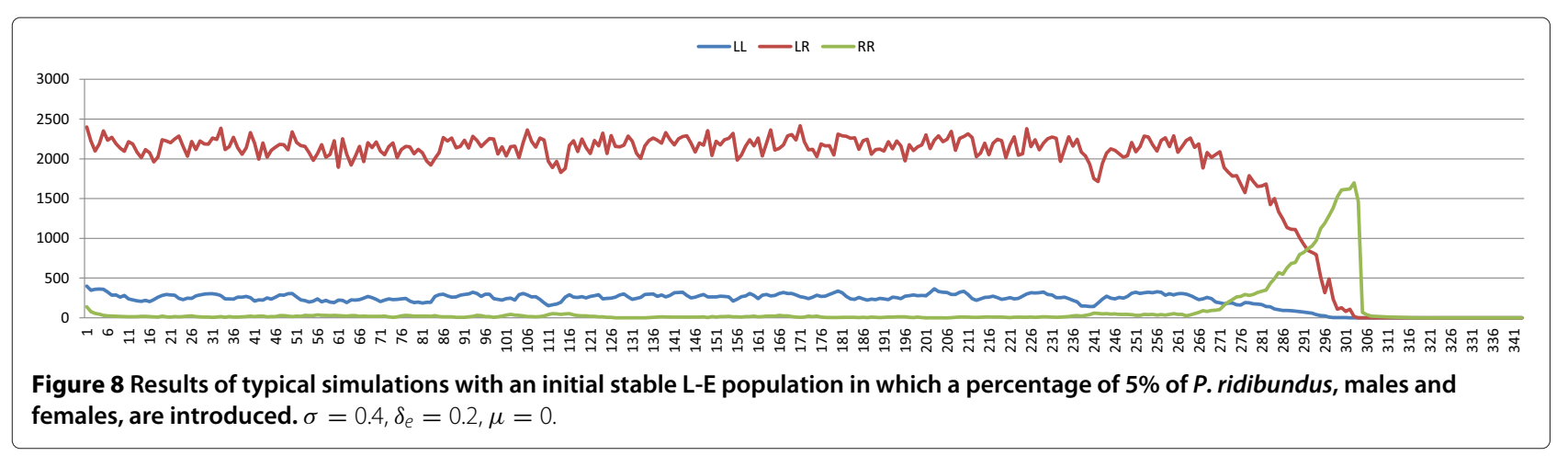

resident $P$. lessonae and $P$. esculentus because we consider that a marshy environment with a low oxygen level, where $P$. lessonae and $P$. esculentus live, is less suitable for $P$. ridibundus.

The results show that, as predicted in [9], the introduced $P$. ridibundus often out-compete the other species resulting in a mono-specific population, when their fitness is comparable to the resident population's. Although the introduction of $P$. ridibundus results in new $R$ hemiclones, which contribute to the genetic diversity of hybrids, our results do not support the hypothesis presented in [5] that this genetic diversity can stabilize the hybridogenetic system. If the fitness of $P$. ridibundus is competitive with the fitness of the resident population $\left(\delta_{e}=0.0\right)$, P. ridibun$d u$ males will survive and $P$. ridibundus often will replace the original population. Note that in this case we also have stable L-E-R complexes as the outcome. This is a system where two independent populations coexist, an L-E complex and a $P$. ridibundus population. The L-E complex is stable due to female preferences and lethal mutations on the $R$ genomes, while the $P$. ridibundus population is stable because of the absence of deleterious mutations, which are purged by selection. The two populations do not cross because the number of individuals in both is high enough to ensure that females of one population in most cases find a preferred male, of the same population, in the set randomly chosen by the best-of- $n$ procedure.
The whole population collapses when the introduced frogs have a low fitness. In this case, $P$. ridibundus individuals will not survive for long, given their unfitness, but $P$. ridibundus frogs, before their death, can introduce $R$ genomes without mutation in the P. esculentus population, thus provoking the collapse of the complex.

Finally, by assuming that $P$. ridibundus are at a considerable disadvantage, the introduced unfit population is out-competed. During their short survival time, $P$. ridibundus females are not able to have a sufficient number of matings with $P$. esculentus males, thus they cannot introduce a sufficient number of $R$ genomes without mutations into the P. esculentus population.

\section{Conclusions}

We have presented an individual-based computational model to study L-E water frog populations, i.e. complexes composed of $P$. lessonae and $P$. esculentus. The individual based model considers not only the genotypes, but also the age of each individual and the average lifespan. In addition, female preferences (implemented by a best-of- $n$ procedure) and ecological selection are considered.

We believe that our results highlight that:

- deleterious mutations in the $R$ genomes strongly contribute, together with sexual preferences, to maintaining the stability of such complexes,

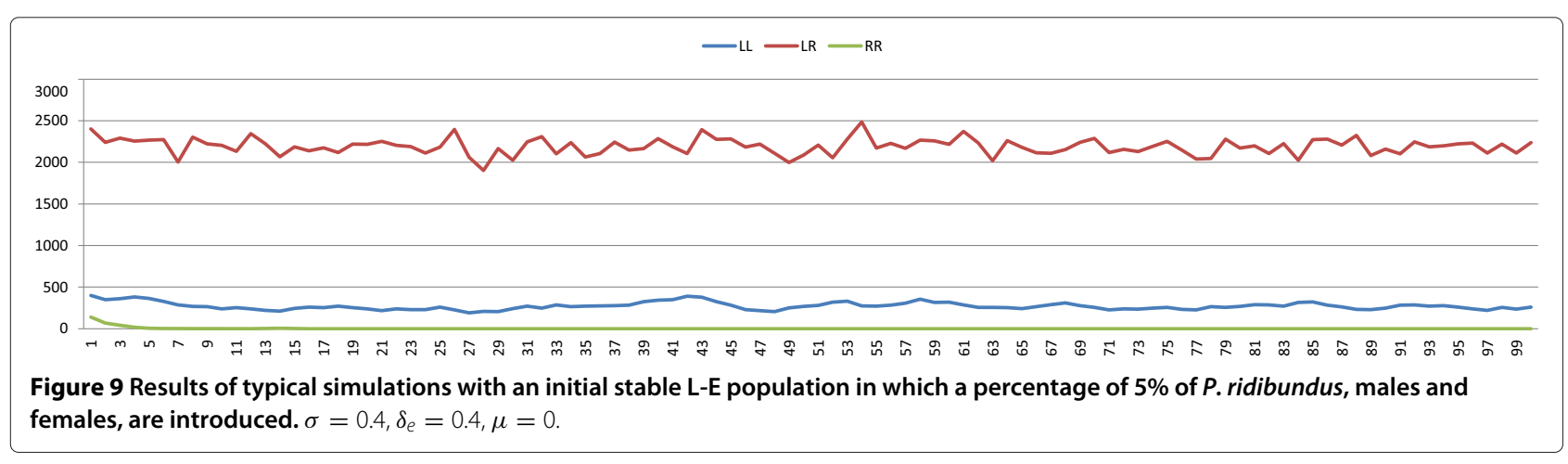


- female sexual choice can contribute to the diffusion of $R$ genomes carrying deleterious mutations in L-E complexes, and

- the introduction of P. ridibundus can destroy L-E complexes.

Competing interests

The authors declare that they have no competing interests.

Authors' contributions

All authors conceived the computational model. PB programmed the simulator and performed the experiments. All authors contributed to write the paper. All authors read and approved the manuscript.

\section{Acknowledgements}

This study has been supported by the University of Pisa. We thank the anonymous referees for their suggestions that allowed us to improve the paper.

Received: 28 February 2014 Accepted: 9 May 2014

Published: 16 May 2014

\section{References}

1. Uzzell $T$, Berger $L$, Günther R: Diploid and triploid progeny from a diploid female of Rana esculenta (Amphibia Salientia). Proc Acad Nat Sci Phila 1975, 127:81-91.

2. Rybacki M, Berger L: Types of water frog populations (Rana esculenta complex) in Poland. Zoosystematics Evol 2001, 77:51-57.

3. Borkin L, Korshunov A, Lada G, Litvinchuk S, Rosanov J, Shabanov D, Zinenko A: Mass occurrence of polyploid green frogs (Rana esculenta complex) in Eastern Ukraine. Russ J Herpetol 2004, 11(3):194-213.

4. Krizmanic̀ I, Ivanovic̀ A: Population systems of the Pelophylax esculentus complex in the southern part of its range. Folia Zoolog 2010, 59(3):215-222.

5. Holsbeek $\mathrm{G}$, Jooris R: Potential impact of genome exclusion by alien species in the hybridogenetic water frogs (Pelophylax esculentus complex). Biol Invasions 2010, 12:1-13.

6. Berger $\mathrm{L}:$ Systematics and hybridization in European green frogs of Rana esculenta complex. J Herpetol 1973, 7:1-10.

7. Hotz H, Mancino G, Bucci-Innocenti S, Ragghianti M, Berger L, Uzzell T: Rana ridibunda varies geographically in inducing clonal gametogenesis in interspecies hybrids. J Exp Zool 1985, 236(2):199-210.

8. Spolsky C, Uzzell T: Evolutionary history of the hybridogenetic hybrid frog Rana esculenta as deduced from mtDNA analyses. Mol Biol Evol 1986, 3:44-56

9. Vorburger $\mathrm{C}$, Reyer $\mathrm{HU}$ : A genetic mechanism of species replacement in European waterfrogs? Conserv Genet 2003, 4(2):141-155.

10. Schmeller $D$ : Tying ecology and genetics of hemiclonally reproducing waterfrogs (Rana, Anura). Annales Zoologici Fennici 2004, 41 (5):681-687.

11. Marracci S, Ragghianti M: The hybridogenetic Rana (Pelophylax) esculenta complex studied in a molecular context. Ital J Zool 2008 , 75(2):109-112.

12. Lehtonen J, Schmidt DJ, Heubel K, Kokko H: Evolutionary and ecological implications of sexual parasitism. Trends Ecol Evol 2013, 28(5):297-306.

13. Semlitsch RD, Schmiedehausen S, Hotz H, Beerli P: Genetic compatibility between sexual and clonal genomes in local populations of the hybridogenetic Rana esculenta complex. Evol Ecol 1996, 10(5):531-543.

14. Vorburger C: Fixation of deleterious mutations in clonal lineages: evidence from hybridogenetic frogs. Evolution 2001, 55(11):2319-2332.

15. Vorburger $C$ : Non-hybrid offspring from matings between hemiclonal hybrid waterfrogs suggest occasional recombination between clonal genomes. Ecol Lett 2001, 4(6):628-636.

16. Guex GD, Hotz H, Semlitsch RD: Deleterious alleles and differential viability in progeny of natural hemiclonal frogs. Evolution 2002, 56(5):1036-1044.

17. Luquet E, Vorburger C, Hervant F, Joly P, Kaufmann B, Schmeller D, Léna J, Grolet $\mathrm{O}$, Konecny L, Plénet S: Invasiveness of an introduced species: the role of hybridization and ecological constraints. Biol Invasions 2011, 13(8):1901-1915.

18. Christiansen DG, Fog K, Pedersen BV, Boomsma JJ: Reproduction and hybrid load in all-hybrid populations of Rana esculenta water frogs in Denmark. Evolution 2005, 59(6):1348-1361.

19. Christiansen DG, Reyer HU: From clonal to sexual hybrids: genetic recombination via triploids in all-hybrid populations of water frogs. Evolution 2009, 63(7):1754-1768

20. Arioli M, Jakob C, Reyer HU: Genetic diversity in water frog hybrids (Pelophylax esculentus) varies with population structure and geographic location. Mol Ecol 2010, 19(9):1814-1828.

21. Christiansen DG, Jakob C, Arioli M, Roethlisberger S, Reyer HU: Coexistence of diploid and triploid hybrid water frogs: population differences persist in the apparent absence of differential survival. BMCECOl 2010, 10:14.

22. Mezhzherin S, Morozov-Leonov S, Rostovskaya O, Shabanov D, Sobolenko $L$ : The ploidy and genetic structure of hybrid populations of water frogs Pelophylax esculentus complex (Amphibia, Ranidae) of Ukraine fauna. Cytol Genet 2010, 44(4):212-216.

23. Christiansen DG, Reyer HU: Effects of geographic distance, sea barriers and habitat on the genetic structure and diversity of all-hybrid water frog populations. Heredity 2011, 106:1-25.

24. Semlitsch RD, Schmiedehausen S: Parental contributions to variation in hatchling size and its relationship to growth and metamorphosis in tadpoles of Rana lessonae and Rana esculenta. Copeia 1994, 1994(2):406-412.

25. Horat $P$, Semlitsch RD: Effects of predation risk and hunger on the behaviour of two species of tadpoles. Behav Ecol Sociob 1994 34(6):393-401.

26. Plenet $S$, Hervant F, Joly P: Ecology of the hybridogenetic Rana esculenta complex: differential oxygen requirements of tadpoles. Evol Ecol 2000, 14:13-23.

27. Planade B, Lena J, Li H, Plenet S, Guegan J, Thomas F, Hurtrezbousses S, Renaud F, Joly P: Tracking a heterosis effect in the field: tadpole resistance to parasites in the water frog hybridogenetic complex. Parasitology 2009, 136:

28. Neveu A: Suitability of European green frogs for intensive culture: comparison between different phenotypes of the esculenta hybridogenetic complex. Aquaculture 2009, 295(1-2):30-37.

29. Neveu A: Influence of genotype of froglets belonging to the Rana esculenta hybridogenetic complex in relation to learning capacity to eat pellets. Aquaculture 2011, 310(3-4):343-349.

30. Semlitsch RD, Reyer HU: Performance of tadpoles from the hybridogenetic Rana esculenta complex: interactions with pond drying and interspecific competition. Evolution 1992, 46(3):665-676

31. Semlitsch RD: Effects of different predators on the survival and development of tadpoles from the hybridogenetic Rana esculenta complex. Oikos 1993, 67:40-46.

32. Semlitsch RD: Asymmetric competition in mixed populations of tadpoles of the hybridogenetic Rana esculenta complex. Evolution 1993, 47(2):510-519.

33. Hotz H, Semlitsch RD, Gutmann E, Guex GD, Beerli P: Spontaneous heterosis in larval life-history traits of hemiclonal frog hybrids. Proc Natl Acad Sci 1999, 96(5):2171-2176.

34. Tejedo M, Semlitsch RD, Hotz H: Differential morphology and jumping performance of newly metamorphosed frogs of the hybridogenetic Rana esculenta complex. J Herpetol 2000, 34(2):201-210.

35. Peter AK: Survival in adults of the water frog Rana lessonae and its hybridogenetic associate Rana esculenta. Can J Zool 2001, 79(4):652-661.

36. Anholt BR, Hotz H, Guex GD, Semlitsch RD: Overwinter survival of Rana lessonae and its hemiclonal associate Rana esculenta. Ecology 2003, 84(2):391-397.

37. Reyer HU, Niederer B, Hettyey A: Variation in fertilisation abilities between hemiclonal hybrid and sexual parental males of sympatric water frogs (Rana lessonae, R. esculenta, R. ridibunda). Behav Ecol Sociobiol 2003, 54(3):274-284.

38. Tietje GA, Reyer HU, Fox S: Larval development and recruitment of juveniles in a natural population of Rana lessonae and Rana esculenta. Copeia 2004, 2004(3):638-646. 
39. Waelti M, Reyer HU: Food supply modifies the trade-off between past and future reproduction in a sexual parasite-host system (Rana esculenta, Rana lessonae). Oecologia 2007, 152(3):415-424.

40. Lengagne T, Grolet $\mathrm{O}$, Joly P: Male mating speed promote hybridization in the Rana lessonae - Rana esculenta waterfrog system. Behav Ecol Sociobiol 2006, 60(2):123-130.

41. Abt G, Reyer HU: Mate choice and fitness in a hybrid frog: Rana esculenta females prefer Rana lessonae males over their own. Behav Ecol Sociobiol 1993, 32(4):221-228

42. Bergen $\mathrm{K}$, Semlitsch RD, Reyer HU: Hybrid female matings are directly related to the availability of Rana lessonae and Rana esculenta males in experimental populations. Copeia 1997, 1997(2):275-283.

43. Reyer H, Frei G, Som C: Cryptic female choice: frogs reduce clutch size when amplexed by undesired males. Proc Roy Soc Lond B Bio/ Sci 1999, 266(1433):2101-2107

44. Roesli M, Reyer HU: Male vocalization and female choice in the hybridogenetic Rana lessonae/Rana esculenta complex. Anim Behav 2000, 60(6):745-755.

45. Engeler $\mathrm{B}$, Reyer HU: Choosy females and indiscriminate males: mate choice in mixed populations of sexual and hybridogenetic water frogs (Rana lessonae, Rana esculenta). Behav Ecol 2001, 12(5):600-606.

46. Lande R: Models of speciation by sexual selection on polygenic traits. Proc Natl Acad Sci 1981, 78(6):3721-3725.

47. Kirkpatrick M: Sexual selection and the evolution of female choice. Evolution 1982, 36:1-12.

48. Wu Cl: A stochastic simulation study on speciation by sexual selection. Evolution 1985, 39:66-82.

49. Higashi M, Takimoto G, Yamamura N: Sympatric speciation by sexual selection. Nature 1999, 402:523-526.

50. Takimoto $G$, Higashi M, Yamamura N: A deterministic genetic mode for sympatric speciation by sexual selection. Evolution 2000, 54(6):1870-1881.

51. van Doorn GS, Weissing FJ: Ecological versus sexual selection models of sympatric speciation: a synthesis. Selection 2002, 2:17-40.

52. Arnegard ME, Kondrashov AS: Sympatric speciation by sexual selection alone is unlikely. Evolution 2004, 58(2):222-237.

53. Kirkpatrick $M$, Nuismer S: Sexual selection can constrain sympatric speciation. Proc Roy Soc Lond B Biol Sci 2004, 271(1540):687-693.

54. Barbuti R, Maggiolo-Schettini A, Milazzo P, Troina A: A methodology for the stochastic modeling and simulation of sympatric speciation by sexual selection. J Biol Syst 2009, 17(03):349-376.

55. Moore WS, McKay FE: Coexistence in unisexual-bisexual species complexes of Poeciliopsis (Pisces: Poeciliidae). Ecology 1971 52(5):791-799.

56. Heubel KU, Rankin DJ, Kokko H: How to go extinct by mating too much: population consequences of male mate choice and efficiency in a sexual/asexual species complex. Oikos 2009, 118(4):513-520

57. Mee JA, Otto SP: Variation in the strength of male mate choices allows long-term coexistence of sperm-dependent asexuals and their sexual hosts. Evolution 2010, 64(10):2808-2819.

58. Hellriegel $\mathrm{B}$, Reyer HU: Factors influencing the composition of mixed populations of a hemiclonal hybrid and its sexual host. J Evol Biol 2000, 13(6):906-918.

59. Som C, Anholt BR, Reyer HU: The effect of assortative mating on the coexistence of a hybridogenetic waterfrog and its sexual host. Am Nat 2000, 156:34-46.

60. Reyer HU, W alti MO, B attig I, Altwegg R, Hellriegel B: Low proportions of reproducing hemiclonal females increase the stability of a sexual parasite-host system (Rana esculenta, R. lessonae). J Anim Ecol 2004, 73(6):1089-1101.

61. Vorburger C, Schmeller DS, Hotz H, Guex GD, Reyer HU: Masked damage: mutational load in hemiclonal water frogs. In Lost Sex. Edited by Schön I, Martens K, Dijk P. Netherlands: Springer; 2009:433-446.

62. Turner GF, Burrows MT: A model of sympatric speciation by sexual selection. Proc Biol Sci 1995, 260(1359):287-292.

63. Beverton R, Holt S: On the Dynamics of Exploited Fish Populations. Fish and Fisheries Series. London UK: Chapman \& Hall; 1957.

64. Kot M: Elements of Mathematical Ecology. Cambridge UK: Cambridge University Press; 2001
65. Gavrilets S, Vose A, Barluenga M, Salzburger W, Meyer A: Case studies and mathematical models of ecological speciation. 1. Cichlids in a crater lake. Mol Ecol 2007, 16(14):2893-2909.

66. Gavrilets S: Rapid transition towards the division of labor via evolution of developmental plasticity. PLOS Comput Biol 2010, 6(6):e1000805.

67. AlSharawi Z, Rhouma MBH: The discrete Beverton-Holt model with periodic harvesting in a periodically fluctuating environment. Adv Difference Equations 2010:2010. doi:10.1155/2010/215875.

68. Barbuti R, Mautner S, Carnevale G, Milazzo P, Rama A, Sturmbauer C: Population dynamics with a mixed type of sexual and asexual reproduction in a fluctuating environment. BMC Evol Biol 2012, 12:1-13. doi:10.1186/1471-2148-12-49.

69. Barbuti R, Cataudella S, Maggiolo-Schettini A, Milazzo P, Troina A: A probabilistic model for molecular systems. Fundamenta Informaticae 2005, 67:13-27

70. Barbuti R, Maggiolo-Schettini A, Milazzo P, Troina A: A calculus of looping sequences for modelling microbiological systems. Fundamenta Informaticae 2006, 72:21-35.

71. Barbuti R, Maggiolo-Schettini A, Milazzo P, Troina A: Bisimulation congruences in the calculus of looping sequences. In Theoretical Aspects of Computing - ICTAC 2006, Volume 4281 of Lecture Notes in Computer Science. Edited by Barkaoui K, Cavalcanti A, Cerone A. Berlin-Heidelberg: Springer; 2006:93-107.

72. Barbuti R, Maggiolo-Schettini A, Milazzo P, Tiberi P, Troina A: Stochastic calculus of looping sequences for the modelling and simulation of cellular pathways. In Transactions on Computational Systems Biology IX, Volume 5121 of Lecture Notes in Computer Science. Edited by Priami C Berlin-Heidelberg: Springer; 2008:86-113.

73. Barbuti R, Caravagna G, Maggiolo-Schettini A, Milazzo P, Pardini G: The calculus of looping sequences. In Formal Methods for Computational Systems Biology, Volume 5016 of Lecture Notes in Computer Science. Berlin Heidelberg: Springer; 2008:387-423.

74. Barbuti R, Maggiolo-Schettini A, Milazzo P, Troina A: Bisimulations in calculi modelling membranes. Formal Aspect Comput 2008, 20(4-5):351-377.

75. Barbuti R, Maggiolo-Schettini A, Milazzo P, Pardini G: Spatial calculus of looping sequences. Theor Comput Sci 2011, 412(43):5976-6001.

76. Drake JW, Charlesworth B, Charlesworth D, Crow JF: Rates of spontaneous mutation. Genetics 1998, 148(4):1667-1686.

77. Pagano A, Dubois A, Lesbarrères $D$, Lodé $T$ : Frog alien species: a way for genetic invasion? Comptes Rendus Biologies 2003, 326, Supplement 1(0):85-92.

doi:10.1186/1471-2148-14-107

Cite this article as: Bove et al: The role of deleterious mutations in the stability of hybridogenetic water frog complexes. BMC Evolutionary Biology 2014 14:107.

\section{Submit your next manuscript to BioMed Central and take full advantage of:}

- Convenient online submission

- Thorough peer review

- No space constraints or color figure charges

- Immediate publication on acceptance

- Inclusion in PubMed, CAS, Scopus and Google Scholar

- Research which is freely available for redistribution 